\title{
A NEGATIVA do DIREITO À EDUCAÇÃo INFANTIL PELOS TRIBUNAIS DE JUSTIÇA DO BRASIL
}

\author{
The negative of the right to early childhood education by the courts of justice of Brazil
}

La negativa del derecho a la educación infantil por los tribunales de justicia de Brasil

Barbara Cristina Hanauer Taporosky*

Adriana A. Dragone Silveira**

\begin{abstract}
Resumo
O presente artigo objetiva analisar os fundamentos das decisões proferidas pelos Tribunais de Justiça do Brasil em ações coletivas nas quais se requer o direito à educação infantil e os pedidos são negados. Realiza-se uma breve análise da evolução história deste direito no Brasil. Na sequência, analisam-se os fundamentos de 37 decisões selecionadas, no período compreendido entre outubro de 2005 e julho de 2016. Os principais fundamentos adotados apresentam a educação infantil como norma programática, a aplicabilidade da teoria da reserva do possível, a impossibilidade de interferência no orçamento público, a ofensa ao princípio da separação dos poderes,a discricionariedade administrativa, a inexistência de estrutura física necessária ao cumprimento do direito pelo Poder Público, seu não reconhecimento como direito coletivo e, ainda, outras questões relacionadas a questões processuais, tais como o não cumprimento dos requisitos para a concessão da tutela antecipada ou a ausência de comprovação da omissão administrativa. Nas considerações finais, indicase que embora o direito à educação infantil já esteja declarado no ordenamento jurídico brasileiro e enquanto um direito é passível de ser exigido judicialmente, o Poder Judiciário tem se mostrado retroativo para na requisição de sua garantia via judicial.
\end{abstract}

PALAVRAS-CHAVE: Educação infantil. Direito à educação. Judicialização.

\begin{abstract}
The present article aims to analyze the fundamentals of the decisions handed down by the Brazilian Courts of Justice in collective actions in which the right to early childhood education is requiredand the requests are denied. For this purpose, a brief analysis of the evolution of this right in Brazil is carried out. The following is a review of the grounds of 37 selected decisions, in the period between October 2005 and July 2016. The main foundations adopted in the decisions include child education as a programmatic norm, the applicability of the theory of reserve of the possible, the impossibility of interference in the public budget, the offense to the principle of separation of powers, administrative discretion, lack of necessary physical structure the fulfillment of the right by the Government, its nonrecognition as a collective right, and other issues related to procedural issues, such as non-compliance with the requirements for granting early protection or lack of evidence of administrative omission. In the final considerations, it is indicated that although the right to early childhood education is already declared in the Brazilian legal system and while a right is liable to be judicially demanded, the Judiciary has been retroactive to requesting its judicial guarantee.
\end{abstract}

KEYWORDS: Early Childhood Education. Rigth do education. Judicialization.

\footnotetext{
* Mestre em educação, doutoranda em educação pela UFPR. E-mail: barbara86ha@yahoo.com.br

** Doutora em educação, professora do Departamento de Planejamento e Administração Escolar da UFPR e do Programa de pós-graduação em educação, na linha de Políticas Educacionais. E-mail: adrianadragone@yahoo.com.br
} 


\section{Resumen}

El presente artículo tiene por objeto analizar los fundamentos de las decisiones dictadas por los Tribunales de Justicia de Brasil en acciones colectivas en las que se requiere el derecho a la educación infantil y las solicitudes son negadas. Se realiza un breve análisis de la evolución histórica de este derecho en Brasil. En consecuencia, se analizan los fundamentos de 37 decisiones seleccionadas, en el período comprendido entre octubre de 2005 y julio de 2016. Los principales fundamentos adoptados presentan la educación infantil como norma programática, la aplicabilidad de la teoría de la reserva de lo posible, la imposibilidad de interferencia en el presupuesto público, la ofensa al principio de la separación de los poderes, la discreción administrativa, la inexistencia de estructura física necesaria para el cumplimiento del derecho por el poder público, su no reconocimiento como derecho colectivo $\mathrm{y}$, además, otras cuestiones relacionadas con cuestiones de procedimiento, tales como el incumplimiento de los requisitos para la concesión de la tutela anticipada o la ausencia de comprobación de la omisión administrativa. En las consideraciones finales, se indica que aunque el derecho a la educación infantil ya está declarado en el ordenamiento jurídico brasileño y mientras un derecho es pasible de ser exigido judicialmente, el Poder Judicial se ha mostrado retroactivo para solicitar su garantía vía judicial.

PALABRAS CLAVE: Educación Infantil. Derecho a la educación. Legalización.

\section{INTRODUÇÃO}

A educação infantil (EI), enquanto direito das crianças de zero a cinco anos de idade, está prevista na Constituição Federal ( $\mathrm{CF} / 88)$, que reconhece sua oferta como dever do Estado no art. 208, IV, cujo atendimento se dá em creches e pré-escolas. Também é prevista como direito dos trabalhadores nesta mesma carta de direitos, conforme art. $7^{\circ}, \mathrm{XXV}$ da $\mathrm{CF} / 88$ (BRASIL, 1988). Inscrita no art. $4^{\circ}$, II, da Lei de Diretrizes e Bases da Educação Nacional (LDB - Lei $n^{\circ}$ 9.394/1996), é considerada a primeira etapa da educação básica (BRASIL, 1996) e visando o desenvolvimento integral das crianças.

Foi apenas com a $\mathrm{CF} / 88$ que a criança pequena foi reconhecida como sujeito de direito à EI, superando a concepção assistencialista presente nas Constituições anteriores que, quando previam o atendimento às crianças pequenas, faziam-no com base na proteção à infância por meio dos serviços de Assistência Social (LUCAS; MACHADO, 2012). Com a edição da $\mathrm{EC} \mathrm{n}^{\circ}$ 59/2009, a faixa etária de quatro e cinco anos, atendida pela pré-escola nos termos da LDB (BRASIL, 1996), passou a integrar a educação obrigatória, cuja implantação progressiva deveria ter ocorrido, nos termos legais, até o ano de 2016 (BRASIL, 2009).

O Plano Nacional de Educação (PNE - Lei 13.005/2014) prevê como meta universalizar, até 2016 - para cumprimento do determinado na EC n ${ }^{\circ}$ 59/2009 - a EI na préescola e ampliar a oferta à EI nas creches para atender, no mínimo, 50\% (cinquenta por cento) das crianças até três anos até o final da vigência no plano (BRASIL, 2014). É importante ressaltar que ainda há muito a ser feito para a garantia do direito, uma vez que essa meta também estava prevista no PNE de 2001 (Lei 10.172/2001) (BRASIL, 2001), não tendo sido atingida. De acordo com os dados do Instituo Nacional de Estudos e Pesquisas Educacionais Anísio Teixeira (INEP), no ano de 2011, prazo final de vigência deste PNE, 85,7\% das crianças com quatro ou cinco anos frequentavam a escola ou creche, sendo que o percentual de crianças com idades entre zero e três anos, no mesmo período, era de apenas $28,1 \%$. Estes números obtiveram melhoras até o ano de 2015, mas ainda sem atingir as metas previstas: $91 \%$ para as crianças de quatro e cinco anos e $30,6 \%$ para as crianças de zero a três anos (INEP, 2018). 
Portanto, uma vez que reconhecer a EI enquanto um direito significa dizer que é dever do Estado garanti-la (RIZZI; XIMENES, 2010), a necessidade de expansão dessa etapa da educação demonstra que, de fato, o direito não tem sido efetivado para todos. Tanto é assim que, até o ano de 2005, haviam decisões judiciais indicando que a EI não se tratava de um dever do Estado, estando o acesso limitado às vagas disponibilizadas, conforme demonstram, por exemplo, as pesquisas de Rizzi e Ximenes (2010), Silveira (2010), Graciano, Marinho e Fernandes (2006) e Marinho (2009). Ou seja, a EI não era compreendida no Poder Judiciário sob a concepção de direito da criança, mas sim de faculdade do Estado.

No entanto, no ano de 2005, o Supremo Tribunal Federal (STF), no julgamento do Recurso Extraordinário $\mathrm{n}^{\circ} 436.996$, em que constava como recorrente o Ministério Público de São Paulo e recorrido o município de Santo André, reconheceu o dever do poder público de ofertar vagas na EI a todas as crianças de até seis anos de idade que assim necessitassem, sendo dever da Administração a disponibilização de vagas de acordo com a procura (BRASIL, 2005), servindo como precedente para as futuras decisões, a contar daquela data, que seriam proferidas a respeito do tema.

Contudo, mesmo após esta decisão do STF, ainda há casos nos quais este direito é negado pelo Poder Judiciário, mediante o indeferimento dos pedidos de acesso à EI. Sendo assim, o presente artigo objetiva analisar decisões proferidas pelo Poder Judiciário em ações coletivas nas quais o acesso à EI é negado, visando identificar seus fundamentos.

Para tanto, considera-se o direito à EI como um direito coletivo, o que significa dizer que sua titularidade não é de um único indivíduo, mas da sociedade (ARAÚJO, 2013), característica própria dos direitos sociais (LOPES, 2002). Desta forma, seu atendimento coletivo permitiria o benefício de toda a coletividade (ARAÚJO, 2013), evitando-se o privilégio de poucos enquanto outros permanecem sem a proteção estatal (LOPES, 2002). Perante o Poder Judiciário, outrossim, a utilização de instrumentos coletivos de exigibilidade atenderia de melhor forma este direito em virtude da indivisibilidade e unitariedade das decisões, de forma que a política atenda a uma coletividade, como deveria ocorrer se realizada pelo Executivo (SILVEIRA, 2013). Esta concepção, contudo, não exclui a possibilidade de que o direito à EI seja exigido também de forma individual. Contudo, apresenta-se a compreensão de que o atendimento de forma coletiva permite um provimento jurisdicional com mais justiça social (LOPES, 2002).

Partindo, portanto, desta concepção, o presente artigo concentra a análise nas decisões proferidas em ações coletivas, nos 27 Tribunais de Justiça do Brasil, nas quais se requer o acesso à EI. Contudo não se ignora que a negativa também pode ocorrer em decisões proferidas em demandas individuais, o que pode inclusive ser objeto de pesquisas futuras.

Para que seja possível a análise de referidas decisões, apresenta-se primeiramente uma breve discussão história a respeito da EI e de seu reconhecimento enquanto direito à educação no Brasil.

\section{A Educação Infantil como direito}

No Brasil, a origem das instituições de EI está relacionada com a assistência à infância, como resultado das interações entre diversos temas e tempos (infância, trabalho feminino, processo de constituição da sociedade capitalista, urbanização, organização do trabalho industrial) (KUHLMANN JR, 2015). 
$\mathrm{O}$ atendimento à infância ${ }^{1}$, quando disciplinado pelas legislações brasileiras, era realizado com base no amparo e na assistência, conforme se verifica no quadro 1. A LDB de 1961 (Lei Federal no 4.024/1961), foi a primeira legislação a prever a educação pré-escolar, conceituando-a como aquela que se destinava às crianças menores de sete anos de idade (CURY, 1998). No entanto, as constituições que se seguiram continuaram apresentando a noção de assistência à infância e não de direito à educação. As de 1967 e 1969, inclusive, previam a edição de uma lei de Assistência à Infância (CURY, 1998).

\section{QUADRO 1 - PREVISÃO DO ATENDIMENTO À INFÂNCIA NAS LEGISLAÇÕES BRASILEIRAS} ANTERIORES À CF/88

\begin{tabular}{|c|c|}
\hline Norma & Previsão \\
\hline Constituição de 1824 & Silenciada \\
\hline Constituição de 1891 & Silenciada \\
\hline Constituição de 1934 & $\begin{array}{l}\text { Proteção à maternidade e à infância como amparo e condições de } \\
\text { trabalho, com destinação de } 1 \% \text { das rendas tributárias. }\end{array}$ \\
\hline Constituição de 1937 & $\begin{array}{l}\text { Previsão de cuidados por parte do Estado àqueles que não tiverem } \\
\text { recursos. }\end{array}$ \\
\hline $\begin{array}{l}\text { Lei de Proteção à } \\
\text { Maternidade, à Infância e à } \\
\text { Adolescência de } 1940\end{array}$ & $\begin{array}{l}\text { Previsão de normas de proteção à maternidade, infância e adolescência, } \\
\text { com o estabelecimento de serviços públicos visando assegurar uma } \\
\text { maternidade sadia desde a concepção até a criação dos filhos. Cria o } \\
\text { Departamento Nacional da Criaça, submetido ao Ministério da } \\
\text { Educação e Saúde, que receberia cooperação do Conselho Nacional do } \\
\text { Serviço Social. }\end{array}$ \\
\hline $\begin{array}{l}\text { Consolidação das Leis do } \\
\text { Trabalho de } 1943\end{array}$ & $\begin{array}{l}\text { Previsão de manutenção de escolas maternais e jardins de infância pelo } \\
\text { SESI, SESC, LBA e outras entidades de proteção à infância e à } \\
\text { maternidade para atender especialmente aos filhos das mulheres } \\
\text { empregadas. }\end{array}$ \\
\hline Constituição de 1946 & Previsão de proteção à infância com caráter assistencial \\
\hline LDB de 1961 & $\begin{array}{l}\text { Reconhece o Pré-Escolar com atendimento em escolas maternais e } \\
\text { jardins de infância e ofertados por empresas que empregavam mães } \\
\text { com filhos menores de } 7 \text { anos. }\end{array}$ \\
\hline Constituição de 1967 & Delega à lei a responsabilidade de dispor sobre a assistência à infância. \\
\hline Ato Institucional $n^{\circ} 1 / 1969$ & Delega à lei a responsabilidade de dispor sobre a assistência à infância. \\
\hline LDB de 1971 & $\begin{array}{l}\text { Mantém a LDB de } 1961 \text { e reforça a responsabilidade das empresas na } \\
\text { organização e manutenção do atendimento à infância. }\end{array}$ \\
\hline
\end{tabular}

FONTE: Adaptado de SILVA (2016), com base em CURY (1998).

O atendimento à infância, até então, foi ofertado sob uma concepção assistencialista no Brasil. Kramer (2006) esclarece que iniciativas de órgãos educativos, com a expansão do atendimento na perspectiva de que a EI é um direito da criança, só começaram a ocorrer há pouco mais de 20 anos e visando o atendimento de crianças entre 4 e 6 anos. Tanto é assim, que as primeiras instituições focavam no atendimento dos cuidados médicos e higiênicos ${ }^{2}$ das crianças (KUHLMANN JR., 2015). Encontravam-se, ainda, uma grande correlação de forças

\footnotetext{
${ }^{1}$ Saliente-se que a opção pela utilização do termo "infância" aqui se dá em virtude de ser este o utilizado pelas legislações ao disciplinar o atendimento que seria destinado às crianças. Não se discute, portanto, a concepção atinente ao termo.

${ }^{2}$ A concepção médico-higienista tinha atenção voltada ao combate da mortalidade infantil, encarando as creches como local adequado para exercício dessa política (KUHLMANN JR., 2015).
} 
com as concepções jurídico-políticas ${ }^{3}$ e religiosas na elaboração das políticas voltadas à infância (KUHLMANN JR., 2015) Contudo, segundo Kuhlmann Jr (2015) a polarização do aspecto assistencial ao aspecto educativo acaba por "atribuir à história da EI uma evolução linear, por etapas” (KHULMANN JR., 2015, p. 166), como se a etapa educacional fosse superior e se contrapusesse às demais.

Na década de 1960, o foco voltou-se ao desenvolvimento cognitivo das crianças: a pré-escola começou a ser encarada com um viés preparatório, ante a constatação de que tinha impacto no rendimento das crianças quando de seu ingresso no ensino fundamental, especialmente para aquelas que advinham de um contexto de privação cultural (OESTREICH, 2011). "Acreditava-se ser possível resolver os altos índices de reprovação na primeira série do ensino regular por meio da 'compensação' oferecida, por antecipação, na pré-escola" (CORRÊA, 2007).

$\mathrm{Na}$ década de 1970, a creche era reivindicada como direito das mães trabalhadoras, colocada na pauta pelos movimentos sociais para garantir a atuação das mulheres no mercado de trabalho e na vida política, fruto das reivindicações do Movimento de Lutas por Creches, que surgiu por iniciativa de movimentos populares, feministas e de mulheres (ROSEMBERG, 1984).

Kulhmann Jr. (2015) ressalta que essas reivindicações já incluíam a caracterização da EI como um dever do Estado, respeitando os direitos das crianças e de suas famílias. Oestreich (2011) esclarece que são fruto já da colocação dos movimentos feministas nos espaços formalizados, o que lhes deu força, nas décadas de 1980 e 1990, para propor a creche como um direito não apenas das mães trabalhadoras, mas também das crianças. É nesse momento que a concepção assistencial passa a ser vista como contrária à educacional: buscava-se uma educação de qualidade, denunciando-se a precariedade que estava presente no atendimento das crianças não apenas da creche, mas também da pré-escola (KUHLMANN JR., 2015).

Foi a $\mathrm{CF} / 88$ que contemplou a EI como um direito, como fruto das reivindicações e lutas populares, movimentos sociais e envolvimento de educadores e estudiosos, possibilitando a imposição, ao Estado, do dever de oferta da EI (CURY, 1998). Segundo Cury (1998), a inovação da LDB, ao incluir a EI como primeira etapa da educação básica, trouxe implicações diretas em sua organização que, agora, passa a fazer parte de toda a estrutura da educação brasileira: é a partir dessa integração à educação básica que a União precisou discipliná-la legalmente.

A previsão constitucional foi corroborada, ainda, pela edição do ECA, que reforçou a necessidade de que a EI seja atendida com absoluta prioridade (SILVEIRA, 2014). Mais recentemente, o Marco Legal da Primeira Infância, que entrou em vigor mediante a Lei $\mathrm{n}^{\mathbf{0}}$ 13.257, de 8 de março de 2016, prevê a EI como uma das áreas prioritárias nas políticas públicas para a primeira infância, disciplinando ainda que essa etapa da educação deve ser expandida de forma a assegurar a qualidade de sua oferta (BRASIL, 2016b).

De acordo com a redação original da $\mathrm{CF} / 88$, a EI não era de matrícula compulsória, uma vez que não estava prevista como etapa obrigatória. A EC n ${ }^{\circ} 59 / 2009$ modificou esse cenário ao tornar a faixa etária compreendida entre os 4 e 17 anos obrigatória, atingindo a faixa etária compreendida pela pré-escola, a partir do ano de 2016 (BRASIL, 2009a). Contudo, a ausência da previsão da obrigatoriedade da matrícula não legitima o Estado a ofertar segundo seus critérios de conveniência.

\footnotetext{
${ }^{3}$ A concepção jurídico-política encarava a assistência à infância como "mérito dos que se mostram mais subservientes“ (KUHLMANN JR., 2015, p. 93), segmentando, ainda mais e de forma preconceituosa, a pobreza. A assistência à infância "moralmente abandonada" é necessária por questão de fraternidade e preservação social (KUHLMANN JR., 2015).
} 
A declaração deste direito, embora tenha sido um passo importante no reconhecimento da criança como sujeito de direitos, ainda não é suficiente a garantir todas as suas dimensões. Uma das decorrências é que se tem levado ao conhecimento do Judiciário inúmeros casos justamente requisitando sua efetivação.

Ainda assim há casos em que o próprio Poder Judiciário nega pedidos de acesso à EI realizados mediante demandas coletivas. Silveira (2010) já destacava que a requisição individual, embora mesmo isonômica, tem sido uma estratégia para a requisição judicial do direito à EI frente à negativa das ações coletivas. A negativa destes requerimentos pode indicar que este Poder não tem reconhecido o direito à EI como direito e/ou o não reconhecimento do dever do Estado na oferta desta etapa educacional. Assim, afigura-se relevante identificar os fundamentos utilizados nestas decisões.

\section{Decisões dos Tribunais de Justiça do Brasil em ações coletivas nas quais o acesso à Educação Infantil é negado}

Para o presente artigo foi realizada uma coleta em todos os Tribunais de Justiça do Brasil $^{4}$, visando identificar as decisões proferidas em ações coletivas no período compreendido entre outubro de $2005^{5}$ e julho de 2016. Para tanto, utilizou-se a ferramenta de busca de jurisprudência e, por meio dos descritores "creche", "pré-escola" e "educação infantil", analisados os resultados encontrados inicialmente com a leitura das ementas, a fim de identificar quais casos se tratavam de ações coletivas nas quais se requerida o acesso à EI e, na sequência, a leitura do inteiro teor das decisões visando identificar os casos nos quais o direito à EI era reconhecido, negado ou não analisado.

Foram coletadas 236 decisões em ações coletivas nas quais se requeria o acesso à EI, nos seguintes Tribunais de Justiça: Acre (TJAC), Amapá (TJAP), Pará (TJPA), Rondônia (TJRO), Tocantins (TJTO), Alagoas (TJAL), Bahia (TJBA), Maranhão (TJMA), Paraíba (TJPB), Rio Grande do Norte (TJRN), Sergipe (TJSE), Goiás (TJGO), Mato Grosso (TJMT), Mato Grosso do Sul (TJMS), Espírito Santo (TJES), Minas Gerais (TJMG), Rio de Janeiro (TJRJ), São Paulo (TJSP), Paraná (TJPR), Rio Grande do Sul (TJRS) e Santa Catarina (TJSC). Nos demais Tribunais de Justiça do Brasil não foram encontradas decisões em ações coletivas nas quais se requer o acesso à EI.

Destas decisões, em 42 o direito foi negado. Trata-se de um considerável número de decisões nas quais o direito à EI não tem sido reconhecido pelos Tribunais de Justiça do Brasil, uma vez que a partir do ano de 2005 o STF considerou que sua oferta configura-se enquanto dever do Estado. Portanto, procedeu-se à distribuição temporal destas decisões, com o fim de verificar se a negativa tem aumentado ou reduzido ao longo do tempo, conforme o gráfico 1 abaixo.

A hipótese inicial era de que estas decisões fossem mais frequentes nas datas mais próximas ao reconhecimento da EI como dever do Estado pelo STF, concentrando-se, portanto, nos anos imediatamente posteriores a 2005. Contudo, os achados da presente

\footnotetext{
${ }^{4}$ Optou-se pela busca das decisões proferidas pelos Tribunais de Justiça pois, nos ternos da lei processual civil, todas as decisões proferidas contra o poder público em primeira instância estão sujeitas ao duplo grau de jurisdição. Desta forma, as sentenças proferidas nos casos nos quais se requer o direito à educação infantil em face dos municípios serão necessariamente reanalisadas pelos Tribunais.

5 A data inicial foi escolhida por se referir à decisão proferida pelo STF no julgamento do Recurso Extraordinário ${ }^{\circ}$ 436.996, em que foi reconhecido o dever do Estado na oferta da educação infantil de acordo com a demanda.
} 
pesquisa indicam o contrário, demonstrando que tem ocorrido um aumento destas negativas a partir do ano de 2010, ainda que com algumas variações.

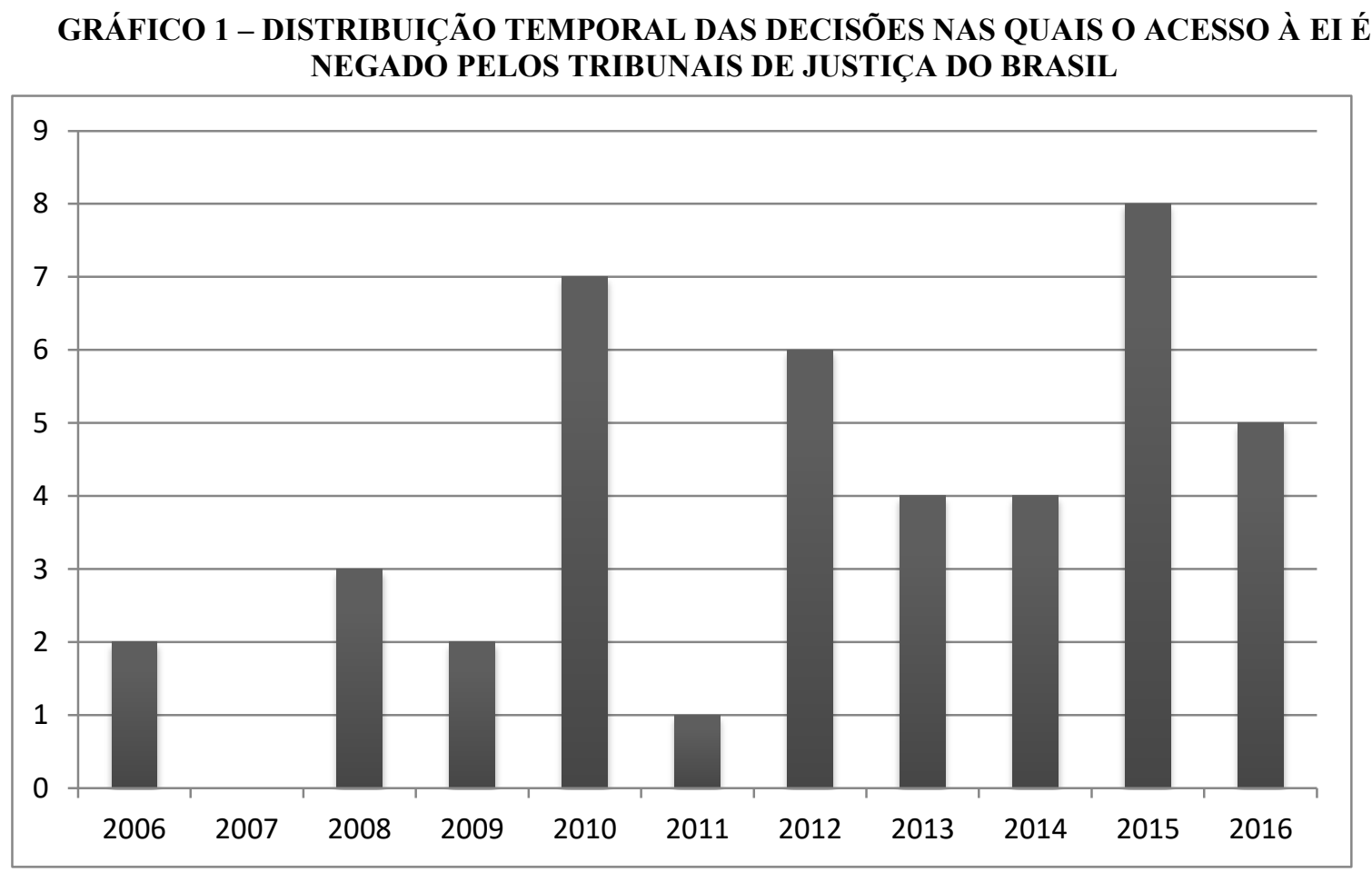

FONTE: Autoria própria (2017).

Estas decisões encontram-se no TJAC, TJGO, TJMT, TJMS, TJMG, TJRJ, TJSP, TJPR, TJRS e TJSC. São estas decisões, portanto, que compõe a análise ora realizada, sendo que serão apresentados os principais fundamentos para a negativa do direito. É importante esclarecer que uma mesma decisão pode contar com mais de um fundamento para negativa do direito, motivo pelo qual estará contemplada em mais de uma categoria apresentada.

\section{Direito à Educação Infantil como norma programática}

Em 4 decisões, proferidas pelo TJAC, TJMT e TJMG constou que o direito à educação das crianças, previsto na $\mathrm{CF} / 88$, trata-se de uma norma programática. Barroso (2006, p. 114) indica que as normas programáticas seriam aquelas que "têm por objeto estabelecer determinados princípios ou fixar programas de ação para o Poder Público". Tratam-se de normas que visam traçar diretrizes que deverão orientar a atuação do Poder Público, de forma que o administrado não pode, a partir das mesmas, exigir algo, uma vez que apenas "explicitam fins, sem indicação dos meios previstos para alcançá-los" (BARROSO, 2006, p. 116).

Contudo, o STF já se manifestou no sentido de que a EI se configura enquanto direito das crianças, que impõe ao Estado o dever da oferta, por se tratar de um direito fundamental (BRASIL, 2005). O autor esclarece que os direitos sociais previstos na CF/88 tratam-se de normas definidoras de direitos, que caracterizam direito subjetivo de seus titulares. Sendo assim, cabe ao indivíduo exigir o cumprimento do direito daquele que tem o dever de 
cumprir. Quando a obrigação de cumprir o direito é do Estado, está-se a frente de um direito subjetivo público (BARROSO, 2006), que é o caso do direito à EI.

Os direitos sociais, portanto, não se configuram como normas programáticas, uma vez que previstos como direitos fundamentais no ordenamento jurídico brasileiro são plenamente exigíveis do Estado (BARROSO, 2006; LOPES, 2002). Barroso (2006) inclusive salienta que a previsão do acesso ao ensino obrigatório gratuito como direito público subjetivo no art. 208, $\S 1^{\circ}$ da $\mathrm{CF} / 88$ não retira o caráter dos demais direitos sociais inscritos na $\mathrm{CF} / 88$ de direitos subjetivos públicos, plenamente exigíveis do Estado.

Desta forma, as decisões que consideram a EI como norma programática não consideram a EI como direito subjetivo das crianças, o que já foi sinalizado pelo STF, entendendo, portanto, que seu cumprimento trata-se de faculdade da administração pública, sem a possibilidade de exigibilidade pelo administrado.

\section{A teoria da reserva do possível e o orçamento público}

$\mathrm{O}$ TJAC proferiu decisão na qual o acesso à EI foi negado sob o fundamento de que no caso deveria ser aplicável a teoria da reserva do possível. Consta da decisão que o ente público demonstrou que tem empenhado esforços a aumentar a oferta desta etapa educacional e que inexistem verbas públicas suficientes - conforme comprovado pelo município nos autos do processo - para garantir a matrícula de todas as crianças residentes na localidade. O TJMG também proferiu decisão indicando que o Poder Judiciário não poderia determinar a implantação de políticas públicas educacionais que impactariam o orçamento municipal, em razão da reserva do possível.

A teoria da reserva do possível constitui-se como um limite fático e jurídico ao cumprimento dos direitos fundamentais, preconizando que não havendo previsão orçamentária, não poderia o Judiciário determinar a realização da política, em virtude da ausência de recursos a viabilizarem seu cumprimento (SILVEIRA, 2013).

No entanto, o orçamento público deve ser pensado visando atingir aos fins constitucionais, dentre os quais o cumprimento dos direitos fundamentais. Desta forma, o cumprimento prioritário dos direitos sociais deve ser contemplado nos orçamentos públicos (CANELA JUNIOR, 2013). O STF sinalizou que a teoria da reserva do possível não é oponível ao direito à EI, especialmente quando a Administração Pública utiliza-se do argumento com o objetivo de descumprir o direito, o que pode causar sua " nulificação ou, até mesmo, aniquilação"(BRASIL, 2006c, p. 11, grifos no original).

O problema é que no julgamento da Arguição de Descumprimento de Preceito Fundamental $n^{\circ} 45$, o STF indicou que a teoria da reserva do possível poderia ser utilizada em caso de motivo justo e objetivamente aferível, ainda que a fundamentação tenha sido pela preponderância dos direitos fundamentais ${ }^{6}$ (BRASIL, 2004). A partir desta interpretação, abre-se a possibilidade de que sejam proferidas decisões no sentido da aplicabilidade da teoria quando comprovada objetivamente a inexistência de recursos no orçamento público, por estarem comprometidos com outras rubricas, como as ora analisadas. Este fato gera uma preocupação no sentido de que pode inviabilizar o requerimento do acesso à EI.

Há ainda outras dez decisões nas quais a negativa do direito está fundamentada na indisponibilidade orçamentária do ente municipal, proferidas pelos TJMT, TJMS, TJMG,

\footnotetext{
${ }^{6}$ Saliente-se que se trata de em uma decisão monocrática, prolatada por um único ministro do STF, em um caso no qual a ação foi arquivada por perda de objeto - ou seja, o mérito da demanda não foi julgado.
} 
TJSP e TJSC., sendo que em quatro destas, considerou-se, ainda, que a determinação de comprometimento de recursos não previsto na peça orçamentária do ente público seria desarrazoada e desproporcional. Em outras duas decisões, proferidas pelo TJRS, o fundamento foi pela impossibilidade de interferência pelo Poder Judiciário em virtude dos limites impostos pela Lei de Responsabilidade Fiscal.

\section{Princípio da separação dos poderes e discricionariedade administrativa}

Dentre as decisões analisadas, há três proferidas pelo TJMG e TJSP na qual o direito foi negado sob o fundamento de que a oferta da EI trata-se de função do Poder Executivo e, portanto, a interferência do Poder Judiciário ocasionaria ofensa ao princípio da separação dos poderes, que está previsto no art. $2^{\circ}$ da $\mathrm{CF} / 88$, por meio do qual cada um dos três poderes possuem funções próprias que são a eles inerentes. Em uma delas, ainda, indicou-se que o atendimento de crianças em creche e pré-escola, ainda que não atenda a toda a demanda manifesta, é suficiente a descaracterizar a omissão do ente público, já que há oferta educacional. Desta forma, caberia ao Poder Executivo executar a lei e, portanto, não poderia o Judiciário determinar ao Executivo como realizá-la.

Contudo, o princípio da separação dos poderes está vinculado à máxima proteção dos direitos fundamentais (ARAÚJO, 2013), sendo que eventual ameaça ou lesão a direito deve ser levada ao conhecimento do Poder Judiciário - art. $5^{\circ}$ da CF/88 (BRASIL, 1988) - que estará apenas cumprindo sua função constitucional caso a reprima (SILVEIRA, 2013). Assim, a ofensa ao direito à EI pode ser objeto de controle pelo Poder Judiciário sem que haja ofensa ao princípio da separação dos poderes.

Há seis decisões, proferidas pelo TJMT, TJMS, TJMG, TJRJ e TJSP nas quais o direito é negado sob o fundamento de que se a oferta da EI é de âmbito discricionário do Poder Público, o que já foi anteriormente indicado por Silveira (2014). Este argumento está diretamente ligado à questão da separação dos poderes, uma vez que a discricionariedade é a liberdade de decisão do administrador dentre várias soluções legais possíveis (PIETRO, 2001) e, portanto, compõe o âmbito da função administrativa, própria do Poder Executivo. Tanto é assim que em seis decisões (proferidas pelo TJMG e TJSP) o indeferimento fundamentou-se conjuntamente na ofensa à discricionariedade administrativa e à separação de poderes. Sendo assim, consta destas decisões que caberia ao administrador público a resolução de como ofertar a EI, o que compreenderia o número de vagas disponibilizadas à população. Neste caso, a interferência do Poder Judiciário caracterizaria uma ingerência indevida em função eminentemente administrativa.

Contudo, Zaneti Jr. (2013) esclarece que o exercício da discricionariedade administrativa não pode impedir ou atrapalhar o exercício de direitos fundamentais. Ademais, o direito à EI trata-se de direito fundamental que deve ser atendido com absoluta prioridade e, portanto, não se encontra no âmbito de discricionariedade da Administração, mas se trata de dever do Estado, como já pontuado anteriormente (SILVEIRA, 2014).

\section{Inexistência de estrutura física}

Em uma decisão proferida pelo TJMT, o requerimento de liminar para abertura vagas na EI não foi deferido sob o fundamento de que o município comprovou não possuir estrutura física e material suficiente para incluir as crianças nas instituições existentes, bem como que 
já está realizando a construção de duas novas unidades para ampliação do atendimento. Já em duas decisões proferidas pelo TJMG indica-se que há nos autos a comprovação de que o ente municipal tem envidado esforços para a ampliação e melhoria da oferta da EI, afigurando-se como desproporcional e desarrazoada decisão determinando o atendimento de mais crianças. Em decisão, proferida pelo TJPR, fundamentou-se no fato de que a ausência de estrutura adequada impediria a concessão do direito em virtude do risco de superlotação e de insalubridade do ambiente destinado às crianças.

A determinação da abertura de vagas pelo Poder Judiciário sem que o município tenha estrutura adequada para atendimento das crianças pode ocasionar problemas relacionados às condições de oferta e superlotação de classes, como já denunciado por Silva (2016). Contudo, decisões como estas também deixam de reconhecer o direito de crianças à EI, na medida em que priorizam quem já está matriculado. Trata-se de um impasse de complicada solução, uma vez que opõe o atendimento às condições de oferta. Todavia, há decisões proferidas pelos Tribunais de Justiça da Paraíba e de Santa Catarina, nas quais o Poder Judiciário apresenta como alternativa a estes casos a celebração de convênios com entidades assistenciais ou particulares para o atendimento de crianças em creches e pré-escolas.

Por fim, encontrou-se ainda um caso no qual o pedido liminar para ampliação de vagas na EI foi suspenso pelo TJSP sob o fundamento da inexistência de estrutura física no município, inclusive pela ausência de vagas no setor privado que pudessem acomodar as crianças em fila de espera, bem como que o município já estava em processo de licitação para construção de novas unidades públicas.

\section{Não reconhecimento do direito à Educação Infantil como direito coletivo}

Silveira (2014) e Corrêa (2014) apontaram que o TJSP negou pedidos realizados em ações coletivas nas quais se requeria o acesso à EI de forma genérica e a um número indeterminado de crianças, sem que houvesse a especificação do número de vagas ou nome das crianças que deveriam ser atendidas. Este fundamento foi encontrado em oito decisões, proferidas pelos TJMT, TJMG e TJSP, sendo que em quatro delas aponta-se que a determinação de ampliação do atendimento sem especificar a quantidade de vagas necessárias geraria ingerência indevida do Poder Judiciário na Administração, violando a discricionariedade do ente público. Em outras duas, o fundamento foi de que geraria graves consequências ao orçamento público.

Estas decisões parecem não reconhecer o direito à EI como direito coletivo, uma vez que não consideram o direito de todas as crianças da sociedade, na faixa etária indicada pela $\mathrm{CF} / 88$. A possibilidade de exigibilidade por esta via visa privilegiar todas as crianças que necessitam de vagas e não daquelas que recorreram diretamente ao Poder Judiciário para garantia do direito.

Esse fundamento apresenta o direito à educação apenas enquanto um direito individual homogêneo, que necessita da especificação de seus titulares para proteção. Essa dificuldade, como bem retratado por Lopes (2002), "deriva do modelo social do mercado, ao qual corresponde um modelo jurídico de relações interpessoais" (LOPES, 2002, p. 129), o que demonstra que ainda se enfrentam resistências ao reconhecimento do direito à educação, enquanto um direito social, como um direito coletivo. 


\section{Outras questões}

Além dos fundamentos de direito apresentados, há questões processuais que são consideradas pelo Poder Judiciário e levam ao indeferimento do direito em si, ou seja, o mérito do pedido. Entre as decisões coletadas, encontraram-se 12 decisões proferidas em sede de agravo de instrumento, recurso proposto contra as decisões de antecipação de tutela em caráter liminar, negando a abertura imediata da vaga, anteriormente à prolação da sentença, em virtude do não cumprimento dos requisitos previstos no art. 273 do Código de Processo Civil de $1973(\mathrm{CPC} / 73)^{7}$.

Ainda, há casos nos quais o Poder Público utiliza-se do expediente da suspensão de liminar, previsto no art. $4^{\circ}$ da Lei $n^{\circ} 8.437 / 1992$, para fazer cessar a eficácia de decisões de antecipação de tutela concedidas em ações coletivas nas quais se requer a garantia do direito à EI. Encontraram-se quatro decisões proferidas pelo TJSP e TJSC em que se suspenderam decisões nas quais se concedera pedidos liminares, com base no fundamento de que sua manutenção ocasionaria lesão a bens públicos em virtude de se determinar política pública custosa aos cofres municipais.

Por fim, há casos nos quais o direito é negado por não haver prova nos autos da omissão administrativa, ou seja, da negativa da matrícula pelo poder público. Contudo, a preocupação com esta decisão reside no fato de que nem sempre é possível a produção desta prova, uma vez que o município pode negar a matrícula e não fornecer nenhum documento ou declaração neste sentido ao administrado que busca o atendimento. Assim, a impossibilidade de comprovar o descumprimento do direito prejudicaria sua exigibilidade perante o sistema de justiça.

\section{CONSIDERAÇÕES FINAIS}

Ainda que o direito à EI tenha sido reconhecido no ordenamento jurídico brasileiro, como fruto de lutas históricas, sua declaração não tem sido suficiente, em muitos casos, para sua garantia, ainda que utilizando sua exigibilidade judicial.

Como demonstrado neste trabalho, ainda há muitas crianças que não têm acessado esta etapa educacional, especialmente na pré-escola que já deveria ter o atendimento universalizado ao final do ano de 2016. Em relação à creche, ainda que a matrícula não seja compulsória, a grande busca ao Poder Judiciário para seu acesso demonstra que o baixo atendimento não se dá apenas por opção das famílias, mas também pela omissão do Poder Público em garantir o acesso à esta subetapa.

O acionamento do Poder Judiciário, especialmente após a manifestação favorável do STF no ano de 2005, apresenta-se como uma solução para o cumprimento deste direito. Contudo, como demonstrado neste trabalho, ainda há diversos casos nos quais nem mesmo este Poder reconhece o direito à EI, especialmente nas demandas coletivas. Ainda que na maior parte das decisões proferidas em ações coletivas o direito seja reconhecido, em pouco mais de um quinto este direito é negado, o que demonstra-se como uma quantia considerável de casos nos quais não tem sido garantido pelos Tribunais de Justiça do Brasil.

\footnotetext{
${ }^{7}$ Lei processual vigente à época da decisão. A partir de 16 de março de 2016 entrou em vigor a Lei 13.105/2015, conhecida como o Novo Código de Processo Civil, que revogou o CPC/73.
} 
Foram encontrados como fundamentos nestas decisões a concepção de que o direito à EI trata-se de norma programática, a aplicabilidade da teoria da reserva do possível e questões relacionadas a limitações orçamentárias e a ofensa ao princípio da separação dos poderes e à discricionariedade administrativa. Estes fundamentos opõem-se às manifestações favoráveis do STF ao reconhecer o direito à EI como dever do Estado e que deve ser atendido com absoluta prioridade. Chama a atenção, especialmente, o considerável número de casos nos quais a teoria da reserva do possível é aplicada, ainda que não declaradamente, mas pelo reconhecimento de impossibilidade de comprometimento do orçamento público.

Em outras decisões, as fundamentações para a negativa estão vinculadas à comprovação da inexistência de estrutura física hábil nos municípios para a ampliação de vagas. Nestes casos, há decisões proferidas em outras ações nas quais os Tribunais apresentam soluções alternativas para que o direito seja garantido às crianças que não estão sendo atendidas.

Há, ainda, decisões nas quais o direito é negado em virtude da ausência de reconhecimento de seu caráter coletivo, como apontado anteriormente nos trabalhos de Silveira (2014) e Corrêa (2014). A tendência apontada pelas autoras em relação aos julgados do TJSP também ocorre no TJMT e no TJMG.

Apresentaram-se ainda como fundamentos para a negativa do direito questões relacionadas à impossibilidade da concessão da tutela antecipada ou da ausência de prova nos autos da omissão administrativa. Estas decisões acabam negando o direito, em seu conteúdo material, por questões relacionadas ao trâmite processual. Em específico as questões relacionadas à ausência de provas da omissão administrativa demonstram-se preocupante na medida em que nem sempre o Poder Público fornece a comprovação quando nega a matrícula de crianças na EI, impedindo, neste caso, a exigibilidade do direito pelo indivíduo frente ao Poder Público.

Por fim, verifica-se que referidas decisões, ainda que sejam em muito superadas por aquelas nas quais o direito é reconhecido pelos Tribunais de Justiça do Brasil, tem aumentado no decorrer dos anos. Sendo assim, afigura-se relevante monitorar como o Poder Judiciário tem se posicionado na garantia deste direito.

\section{REFERÊNCIAS}

ARAÚJO, Fernanda Raquel Thomaz de. Controle judicial de políticas públicas e realinhamento da atividade orçamentária na efetivação do direito à educação: processo coletivo e a cognição do judiciário. 2013. 197 f. Dissertação (Mestrado) - Curso de Direito Negocial, Universidade Estadual de Londrina, Londrina, 2013.

BARROSO, Luís Roberto. O direito constitucional e a efetividade de suas normas - limites e possibilidades da constituição brasileira. Rio de Janeiro: Renovar, 2006.

BRASIL. Constituição (1988). Constituição da República Federativa do Brasil. Brasília, 5 out. 1988.

BRASIL. Emenda Constitucional $n^{\circ} 53$, de 19 de dezembro de 2006. Dá nova redação aos arts. $7^{\circ}, 23,30,206,208,211$ e 212 da Constituição Federal e ao art. 60 do Ato das 
Disposições Constitucionais Transitórias. Brasília, 20 dez. 2006. Disponível em: $<$ http://www.planalto.gov.br/ccivil_03/Constituicao/Emendas/Emc/emc53.htm>. Acesso em: 19 jan. 2016.

BRASIL. Emenda Constitucional $n^{\circ} 59$, de 11 de novembro de 2009. Acrescenta $\S 3^{\circ}$ ao art. 76 do Ato das Disposições Constitucionais Transitórias para reduzir, anualmente, a partir do exercício de 2009, o percentual da Desvinculação das Receitas da União incidente sobre os recursos destinados à manutenção e desenvolvimento do ensino de que trata o art. 212 da Constituição Federal, dá nova redação aos incisos I e VII do art. 208, de forma a prever a obrigatoriedade do ensino de quatro a dezessete anos e ampliar a abrangência dos programas suplementares para todas as etapas da educação básica, e dá nova redação ao $\S 4^{\circ}$ do art. $211 \mathrm{e}$ ao $\S 3^{\circ}$ do art. 212 e ao caput do art. 214, com a inserção neste dispositivo de inciso VI.. Brasília, 12 nov. 2009. Disponível em: $<$ http://www.planalto.gov.br/ccivil_03/constituicao/emendas/emc/emc59.htm>. Acesso em: 19 jan. 2016.

BRASIL. Instituto Nacional de Pesquisas Educacionais Anísio Teixeira. Diretoria de estudos educacionais. Relatório do $1^{\circ}$ ciclo de monitoramento das metas do PNE: biênio 2014-2016. Brasília: INEP, 2016a.

BRASIL. Lei federal $n^{\circ} 13.257$, de 8 de março de 2016. Dispõe sobre as políticas públicas para a primeira infância e altera a Lei no 8.069, de 13 de julho de 1990 (Estatuto da Criança e do Adolescente), o Decreto-Lei no 3.689, de 3 de outubro de 1941 (Código de Processo Penal), a Consolidação das Leis do Trabalho (CLT), aprovada pelo Decreto-Lei no 5.452, de 1 o de maio de 1943, a Lei no 11.770, de 9 de setembro de 2008, e a Lei no 12.662, de 5 de junho de 2012. Brasília, 2016b. Disponível em: $<$ http://www.planalto.gov.br/ccivil_03/_ato2015-2018/2016/lei/113257.htm> Acesso em: 14 mai. 2017.

BRASIL. Lei federal $n^{\circ}$ 8.069, de 13 de julho de 1990. Estatuto da criança e do adolescente. Rio de Janeiro: Imprensa Oficial, 1990.

BRASIL. Lei federal $n^{\circ}$ 9.394. Estabelece as diretrizes e bases da educação nacional. Brasília, 23 dez. 1996.

BRASIL. Lei $n^{\circ}$ 10.172, de 9 de janeiro de 2001. Aprova o plano nacional de educação e dá outras providências. Brasília, 2001. Disponível em: $<$ http://www.planalto.gov.br/ccivil_03/leis/leis_2001/110172.htm> Acesso em: 22 jun. 2016.

BRASIL. Lei $n^{o}$ 13.005, de 25 de junho de 2014. Aprova o Plano Nacional de Educação - PNE e dá outras providências. Brasília, 2014. Disponível em: <http://www.planalto.gov.br/ccivil_03/_ato2011-2014/2014/lei/113005.htm>. Acesso em: 19 jan. 2016. 
BRASIL. Lei $n^{o}$ 13.105, de 16 de março de 2015. Código de Processo Civil. Brasília, 2015. Disponível em: <http://www.planalto.gov.br/ccivil_03/_ato2015-2018/2015/lei/113105.htm>. Acesso em: 19 jan. 2016.

BRASIL. Lei $n^{\circ}$ 5.869, de 11 de janeiro de 1973. Código de Processo Civil. Disponível em: $<$ http://www.planalto.gov.br/ccivil_03/leis/L5869compilada.htm>. Acesso em: 19 jan. 2016.

BRASIL. Lei $n^{\circ}$ 8.437, de 30 de junho de 1992. Dispõe sobre a concessão de medidas cautelares contra atos do Poder Público e dá outras providências. Brasília, 1992. Disponível em: < http://www.planalto.gov.br/ccivil_03/leis/18437.htm>. Acesso em: 26 de dezembro de 2017.

BRASIL. Supremo Tribunal Federal. Arguição de Descumprimento de Preceito Fundamental n. ${ }^{\circ}$ 45. Recorrente: Presidente da República. Recorrido: Partido da Social Democracia Brasileira. Relator: Ministro Celso de Melo. Brasília, 29 de abril de 2004. Diário de Justiça da União. Brasília, 04 maio 2004.

BRASIL. Supremo Tribunal Federal. Recurso Extraordinário $\mathrm{n}^{\mathrm{o}}$ 436996. Recorrente: Ministério Público do Estado de São Paulo. Recorrido: Município de Santo André. Relator: Ministro Celso de Mello. Brasília, 26 de janeiro de 2005. Diário de Justiça da União. Brasília, 07 nov. 2005.

CANELA JUNIOR, Osvaldo. O orçamento e a "reserva do possível': dimensionamento no controle judicial de políticas públicas. In: GRINOVER, Ada Pellegrini; WATANABE, Kazuo. O controle jurisdicional de políticas públicas. Rio de Janeiro: Forense, 2013. 2. ed.

CORRÊA, Bianca. A educação infantil. In. Organização do ensino no Brasil. São Paulo: Xamã, 2007. 2. ed. P. 13-30.

CORRÊA, Luiza Andrade. A judicialização da política pública de educação infantil no Tribunal de Justiça de São Paulo. 2014. 236 f. Dissertação (Mestrado) - Curso de Direito, Universidade de São Paulo. São Paulo, 2014.

CURY, Carlos Roberto Jamil. A educação infantil como direito. In BRASIL. Ministério da Educação. Subsídios para credenciamento e funcionamento de instituições de educação infantil. 1998. v. 2. p. 9-15.

GRACIANO, Mariângela; MARINHO, Carolina; FERNANDES, Fernanda. As demandas judiciais por educação na cidade de São Paulo. In HADDAD, Sérgio; GRACIANO, Mariângela. A educação entre os direitos humanos. Campinas: Autores Associados, 2006. P. 156-196. 
INSTITUTO NACIONAL DE ESTUDOS E PESQUISAS EDUCACIONAIS ANÍSIO TEIXEIRA. Painel de indicadores do plano nacional de educação. Brasília, 2018. Disponível em: <http://inepdata.inep.gov.br/analytics/saw.dll?Dashboard>. Acesso em: 20 fev. 2018.

KRAMER, Sônia. As crianças de 0 a 6 anos nas políticas educacionais no Brasil: educação infantil e/é fundamental. Educ. Soc. Campinas, n. 96, v. 27, p. 797-818, out. 2006.

KUHLMANN JR., Moysés. Infância e educação infantil: uma abordagem histórica. Porto Alegre: Mediação, 2015. 7. ed.

LOPES, José Reinaldo de Lima. Direito subjetivo e direitos sociais: o dilema do judiciário no estado social de direito. In: FARIA, José Eduardo (Org.). Direitos Humanos, Direitos Sociais e Justiça. São Paulo: Malheiros Editores, 2002.

LUCAS, Maria Angélica Olivo Francisco; MACHADO, Maria Cristina Gomes. Percalços da Educação Infantil como direito da criança: análise da história e da legislação das décadas de 1980 e 1990. Prax. Educ., [s.1.], v. 7, n. 1, p.107-128, 28 jun. 2012. Universidade Estadual de Ponta Grossa (UEPG). DOI: 10.5212/praxeduc.v.7i1.0006. Disponível em: $<$ http://www.revistas2.uepg.br/index.php/praxiseducativa/article/view/2963>. Acesso em: 09 jan. 2016.

MARINHO, Carolina Martins. Justiciabilidade dos direitos sociais: análise de julgados do direito à educação sob o enfoque da capacidade institucional. 2009. 120 f. Dissertação (Mestrado) - Curso de Direito, Universidade de São Paulo, São Paulo, 2009.

OESTREICH, Marlise. Democratização da educação infantil no município de Florianópolis: uma análise das "creches ampliadas". 2011. 209 f. Dissertação (mestrado). Curso de Educação, Universidade Federal de Santa Catarina, Florianópolis, 2011.

PIETRO, Maria Sylvia Zanella di. Direito administrativo. São Paulo: Atlas, 2001. 13. ed.

RIZZI, Ester; XIMENES, Salomão de Barros. Litigância estratégica para a promoção de políticas públicas: as ações em defesa do direito à educação infantil em São Paulo. In: FRIGO, Darci; PRIOSTE, Fernando; ESCRIVÃO FILHO, Antônio Sérgio. Justiça e direitos humanos: experiências de assessoria jurídica popular. Curitiba: Terra de Direitos, 2010. p. 105-127.

ROSEMBERG, Fúlvia. O movimento de mulheres e a abertura política no Brasil: o caso da creche. Cadernos de pesquisa. São Paulo, n. 51, nov. 1984, p. 73-79.

SILVA, Edina PischarakaItcak Dias da. Os efeitos da atuação do sistema de justiça nas políticas de educação infantil: estudo de caso no município de Araucária/Pr. Dissertação 
(mestrado). - Pós-Graduação em Educação da Universidade Federal do Paraná. Curitiba, 2016.

SILVEIRA, Adriana Aparecida Dragone. Conflitos e consensos na exigibilidade judicial do direito à educação básica. Educ. Soc., [s.1.], v. 34, n. 123, p.371-387, jun. 2013. FapUNIFESP (SciELO). DOI: 10.1590/s0101-73302013000200003. Disponível em: $<$ http://www.scielo.br/scielo.php?script=sci_arttext\&pid=S0101-73302013000200003>. Acesso em: 09 jan. 2016.

SILVEIRA, Adriana Aparecida Dragone. Exigibilidade do direito à educação infantil: uma análise da jurisprudência. In. SILVEIRA, Adriana Dragone; GOUVEIA, Andréa Barbosa; SOUZA, Ângelo Ricardo de. Conversas sobre políticas educacionais. Curitiba: Appris, 2014. p. 167-188.

SILVEIRA, Adriana Aparecida Dragone. O direito à educação de crianças e adolescentes: análise da atuação do Tribunal de Justiça de São Paulo (1991-2008). 2010. 303 f. Tese (Doutorado) - Faculdade de Educação da Universidade de São Paulo, São Paulo, 2010.

ZANETI JR., Hermes. A teoria da separação de poderes e o estado democrático constitucional: funções de governo e funções de garantia. In: GRINOVER, Ada Pellegrini; WATANABE, Kazuo. O controle jurisdicional de politicas públicas. Rio de Janeiro: Forense, 2013. 2. ed. p. 33-72.

Recebido em: 12/02/2018

Aceito em: 06/04/2018 